\title{
Diallel Anaysis of Oil Production Components in Peanut (Arachis hypogaea L.)
}

\author{
Jeffrey N. Wilson, ${ }^{1}$ Michael R. Baring, ${ }^{1}$ Mark D. Burow, ${ }^{2}$ \\ William L. Rooney, ${ }^{1}$ and Charles E. Simpson ${ }^{3}$ \\ ${ }^{1}$ Texas A\&M AgriLife Research, Texas A\&M System, College Station, TX 77843, USA \\ ${ }^{2}$ Texas A\&M AgriLife Research, Texas A\&M System, Lubbock, TX 79403, USA \\ ${ }^{3}$ Texas A\&M AgriLife Research, Texas A\&M System, Stephenville, TX 79401, USA \\ Correspondence should be addressed to Jeffrey N. Wilson; jwilson@ag.tamu.edu
}

Received 19 May 2013; Accepted 3 August 2013

Academic Editor: Othmane Merah

Copyright (C) 2013 Jeffrey N. Wilson et al. This is an open access article distributed under the Creative Commons Attribution License, which permits unrestricted use, distribution, and reproduction in any medium, provided the original work is properly cited.

Peanut (Arachis hypogaea L.) has the potential to become a major source of biodiesel, but for market viability, peanut oil yields must increase. Oil yield in peanut is influenced by many different components, including oil concentration, seed mass, and mean oil produced per seed. All of these traits can potentially be improved through selection as long as there is sufficient genetic variation. To assess the variation for these traits, a diallel mating design was used to estimate general combining ability, specific combining ability, and heritability. General combining ability estimates were significant for oil concentration, weight of 50 sound mature kernels (50 SMK), and mean milligrams oil produced per SMK (OPS). Specific combining ability was significant for oil concentration. Reciprocal effects were detected for OPS. Narrow-sense heritability estimates were very high for oil concentration and 50 SMK and low for OPS. The low OPS heritability estimate was caused by the negative correlation between oil concentration and seed size. Consequently, oil concentration and seed mass alone can be improved through early generation selection, but large segregating populations from high oil crosses will be needed to identify progeny with elevated oil concentrations that maintain acceptable seed sizes.

\section{Introduction}

The cultivated peanut (Arachis hypogaea L.) is an important annual oilseed crop planted as a food group throughout the world. In the USA, over one million acres of peanut were planted in 2012 [1]. Peanut has potential as a source of biofuel, but because it must compete for food use, increases in oil production on a per acre basis are essential if the crop is to be used as a source of oil for biofuel conversion.

Previous studies conducted with peanut indicate that selectable genetic variation exists for oil content. Additive effects (general combining ability (GCA)) were more important than nonadditive effects (specific combining ability (SCA)) for determining oil content in studies measuring $F_{1}$ populations [2,3] and an $F_{2}$ population [4]. The performance of parental lines was generally a good predictor of hybrid oil content $[3,4]$. Cytoplasmic (maternal) effects were significant in the $F_{1}$ generation in a study by Isleib et al. [3] but were much less pronounced in a study using $F_{2} \mathrm{~s}$ [4].

Layrisse et al. [4] observed a significant positive correlation between oil content and yield based on GCA effects. Correlations between oil content and seed mass, pod weight, and pod length were not significant. Dwivedi et al. [5] determined that high oil content can be maintained when indirectly selecting for large seed size. Other studies have reported negative correlations between seed size and oil content in peanut [6, 7]. In corn (Zea mays), Miller et al. [8] observed reductions in kernel mass only when oil contents increased by more than $7 \%$. The correlation between oil content was seed mass slightly negative in high oil content rapeseed (Brassica napus) [9] but was positive in two studies involving soybean (Glycine max) $[10,11]$. 
Seed mass is not a critical factor for processors when peanuts are processed for oil [5]. However, there is a positive association between pod weight and yield [4] and seed mass and yield [12]. The objectives of this study were to determine genetic variance components for oil concentration, seed mass of sound mature kernels (SMK), and mean milligrams oil produced per SMK through a diallel mating design and to assess the relationship between oil concentration and seed mass in segregating progeny. The goal is to maximize seed mass and oil production in early generations of germplasm evaluation for biodiesel.

\section{Materials and Methods}

2.1. Plant Material and Experimental Design. A four-parent diallel cross, including reciprocals, was made in a greenhouse in College Station in 2008 and 2009. Individual $F_{1}$ seeds were increased in the greenhouse and a field site. Seed collected from individual $F_{1}$ plants was pooled to provide enough $F_{2}$ seed for the experiment. Sixteen $F_{2}$ seed were planted by hand in $2.4 \mathrm{~m}$ long twin row plots arranged in a randomized complete block design with four replications for each cross in 2010 at the Texas A\&M University research farm in College Station, TX, USA. Standard agronomic and pest control practices were employed throughout the growing season, and plots were irrigated. The following parents were selected because of known variation in seed size and oil concentration:

(1) Tamrun OL01 [13]: large seeded (33 to $39 \mathrm{~g} / 50$ seed), adapted runner variety with oil concentration between 430 and $460 \mathrm{~g} \mathrm{~kg}^{-1}$;

(2) Tamrun OL07 [14]: adapted runner variety with large sized seed ( 33 to $35 \mathrm{~g} / 50$ seed) and oil concentration between 470 and $490 \mathrm{~g} \mathrm{~kg}^{-1}$;

(3) Lub 268: advanced early maturing runner breeding line, medium seed size ( 29 to $31 \mathrm{~g} / 50$ seed) with oil concentration between 500 and $530 \mathrm{~g} \mathrm{~kg}^{-1}$;

(4) 31-08-05-02: runner breeding line with pedigree Florunner ${ }^{2} / /$ TxAG-6 [15]/Florunner $\mathrm{BC}_{3}$; small seeded (26 to $28 \mathrm{~g} / 50$ seed) with oil concentration above $550 \mathrm{~g} \mathrm{~kg}^{-1}$. Elevated oil concentration is derived from TxAG-6, and an amphidiploid is derived from interspecific wild-species crosses.

At maturity, plants were harvested individually, and seed was dried to $5 \%$ moisture content. A sample of 50 sound mature kernels (50 SMK) for each plot was randomly selected from seed that would not pass through a $6 \times 17 \mathrm{~mm}$ slotted screen. This SMK sample was weighed, and $20 \mathrm{~g}$ of seed was used to estimate oil content using nuclear magnetic resonance (NMR), which measures total oil content on a percentage dry-weight basis. These readings were converted to oil concentrations in $\mathrm{g} \mathrm{kg}^{-1}$. Oil yield per SMK (OPS) in milligrams was calculated by multiplying percent oil content by $50 \mathrm{SMK}$ weight in grams, divided by 50 and multiplied by 1000 .

To test for genotype differences, an analysis of variance for each measured parameter was performed via Proc GLM (SAS
TABLE 1: Mean of oil concentration in $\mathrm{g} \mathrm{kg}^{-1}$, weight of 50 sound mature kernels (50 SMK) in grams, and mean milligrams oil produced per SMK (OPS) of $F_{2}$ progeny and parents in a four-parent diallel of peanut.

\begin{tabular}{|c|c|c|c|}
\hline \multirow{3}{*}{ Pedigree } & \multicolumn{3}{|c|}{ Trait } \\
\hline & Oil concentration & $50 \mathrm{SMK}$ & OPS \\
\hline & $\mathrm{g} \mathrm{kg}^{-1}$ & $\mathrm{~g}$ & $\mathrm{mg}$ \\
\hline $31-08-05-02$ & $558 a^{*}$ & $27.4 \mathrm{i}$ & $303 \mathrm{bc}$ \\
\hline 31-08-05-05 × Lub 268 & $521 b$ & 28.5hi & $297 b c$ \\
\hline Lub $268 \times 31-08-05-05$ & $520 \mathrm{~b}$ & $29.5 \mathrm{gh}$ & $307 \mathrm{abc}$ \\
\hline Lub 268 & $507 c$ & 30.4 fgh & $308 \mathrm{abc}$ \\
\hline Tamrun OL07 × 31-08-05-05 & $504 c$ & 29.6gh & $298 b c$ \\
\hline Tamrun OL01 × 31-08-05-05 & $503 c$ & $29.8 \mathrm{gh}$ & $300 \mathrm{bc}$ \\
\hline 31-08-05-05 × Tamrun OL07 & $496 \mathrm{~cd}$ & $30.0 \mathrm{gh}$ & $296 b c$ \\
\hline 31-08-05-05 × Tamrun OL01 & $495 c d$ & $31.4 \mathrm{efg}$ & $311 \mathrm{ab}$ \\
\hline Lub $268 \times$ Tamrun OL07 & 483de & 32def & $309 a b$ \\
\hline Tamrun OL07 × Lub 268 & $479 \mathrm{e}$ & $30.4 \mathrm{fgh}$ & 291c \\
\hline Tamrun OL07 & $477 \mathrm{e}$ & $33.7 \mathrm{bcd}$ & $322 \mathrm{a}$ \\
\hline Tamrun OL07 × Tamrun OL01 & 471ef & $34.3 \mathrm{abc}$ & $323 a$ \\
\hline Tamrun OL01 × Tamrun OL07 & $465 f g$ & $33.2 \mathrm{cde}$ & $308 \mathrm{abc}$ \\
\hline Tamrun OL01 × Lub 268 & $458 \mathrm{~g}$ & 33.1cde & $304 \mathrm{bc}$ \\
\hline Lub $268 \times$ Tamrun OL01 & $455 \mathrm{gh}$ & $35.4 \mathrm{ab}$ & $322 \mathrm{a}$ \\
\hline Tamrun OL01 & $446 \mathrm{~h}$ & $35.8 \mathrm{a}$ & $311 \mathrm{ab}$ \\
\hline Coefficient of variation (\%) & 1.8 & 4.3 & 4.0 \\
\hline
\end{tabular}

Institute Inc., 2008, Ver. 9.2, Cary, NC, USA). Fisher's protected LSD test was used to determine if differences existed among plot means at the $5 \%$ level of significance.

2.2. Statistical Analysis Using the Griffing Model. The diallel data for each parameter was subjected to a fixed effect analysis using model I, method 1 of Griffing [16]. Using mean sums of squares estimates, GCA effects for each parent, SCA effects for each cross, and reciprocal effects were calculated using DIALLEL software [17]. Griffing's analyses were used to calculate narrow sense heritability $\left(h^{2}\right)$ by dividing GCA by total genetic effects plus error. Phenotypic correlation between oil concentration and 50 SMK across all populations was computed using PROC CORR of SAS.

\section{Results}

Analyses of variance indicated significant genotype differences for oil concentration $(P<0.0001)$, 50 SMK $(P<$ $0.0001)$, and OPS $(P=0.011)$. Plot means for the three traits are presented in Table 1. Compared to oil concentration and $50 \mathrm{SMK}$, variation for OPS was limited. Across all $F_{2}$ progeny, oil concentration tended to decrease as $50 \mathrm{SMK}$ increased with a correlation $(r)$ of $-0.45(P<0.0001)$.

Data indicate that GCA is important in the inheritance of all three traits (Table 2). GCA is analogous to additive genetic effects. Dominance effects, tested by SCA, were also significant in the inheritance of oil concentration. However, 
TABLE 2: Griffing's analyses of variance and narrow-sense heritability estimates $\left(h^{2}\right)$ for oil concentration in $\mathrm{g} \mathrm{kg}^{-1}$, weight of 50 sound mature kernels (50 SMK) in grams, and mean milligrams oil produced per SMK (OPS) in a four-parent $F_{2}$ diallel of peanut.

\begin{tabular}{lcccc}
\hline Source & df & $\begin{array}{c}\text { Oil concentration } \\
\text { Mean square }\end{array}$ & $\begin{array}{c}50 \text { SMK } \\
\text { Mean square }\end{array}$ & $\begin{array}{c}\text { OPS } \\
\text { Mean square }\end{array}$ \\
\hline Blocks & 3 & 168.1 & 4.87 & $442.8^{*}$ \\
Genotypes & 15 & $3236.1^{* *}$ & $24.71^{* *}$ & $359.8^{*}$ \\
GCA & 3 & $14779.6^{* *}$ & $107.98^{* *}$ & $508.5^{*}$ \\
SCA & 6 & $628.3^{* *}$ & 3.65 & 286.4 \\
Reciprocal & 6 & 72.1 & 4.14 & $358.9^{*}$ \\
Error & 45 & 78.1 & 1.87 & 149.8 \\
\hline$h^{2}$ & 0.95 & 0.88 & 0.29 \\
\hline \\
r,** indicate terms that are significant at the 5 and 1\% levels of probability, \\
respectively.
\end{tabular}

TABLE 3: Estimates of GCA effects and standard errors for oil concentration in $\mathrm{g} \mathrm{kg}^{-1}$, weight of 50 sound mature kernels (50 SMK) in grams, and mean milligrams oil produced per SMK (OPS) in a four-parent $F_{2}$ diallel of peanut.

\begin{tabular}{lccc}
\hline & & Trait & \\
Parent & Oil concentration & $50 \mathrm{SMK}$ & $\mathrm{OPS}$ \\
& $\mathrm{g} \mathrm{kg}^{-1}$ & $\mathrm{~g}$ & $\mathrm{mg}$ \\
\hline Tamrun OL01 & $-22.3^{* *}$ & $2.06^{* *}$ & $4.30^{*}$ \\
Tamrun OL07 & $-8.0^{* *}$ & $0.58^{* *}$ & 1.86 \\
Lub 268 & 1.7 & -0.31 & -1.23 \\
$31-08-05-02$ & $28.6^{* *}$ & $-2.33^{* *}$ & $-4.92^{* *}$ \\
\hline SE $\left(g_{i}\right)$ & 1.4 & 0.21 & 1.87 \\
*,** $_{\text {indicate terms that are significant at the } 5 \text { and } 1 \% \text { levels of probability, }}$ \\
respectively.
\end{tabular}

the ratio of GCA to SCA indicated that additive effects were more important than dominance effects, particularly for oil concentration and 50 SMK. Reciprocal effects were significant for OPS, and $h^{2}$ estimates were low for OPS compared to oil concentration and 50 SMK.

As expected, the high oil parent 31-08-05-02 gave the highest GCA estimated for oil concentration (Table 3). However, the GCA for weight of 50 SMK and OPS was negative for this breeding line. Tamrun OL07 and Tamrun OL01 had negative GCA values for oil concentration and had positive GCA values for 50 SMK and OPS. SCA effects observed in this study tended to vary widely for each parent and trait depending on the cross (Table 4). None of the progeny populations had positive SCA values for all three traits. Tamrun OL07 had negative SCA values for all traits in crosses with Lub 268 and 31-08-05-02. SCA effects cannot be fixed in inbred peanut genotypes.

\section{Discussion}

The diallel cross is a powerful tool to study the various variance components of the genetic systems controlling a quantitative trait. The diallel analysis, as outlined by Griffing [16], partitions phenotypic variation into genotypic and error variation and further divides genotypic variation into additive and dominance components. These values can then be used to calculate heritability estimates, draw inferences about the genetic system, and determine the most efficient breeding procedures.

Diallel analyses, along with other mating designs, are based on several assumptions with regard to the genetic system. The failure of one or more of these assumptions may influence and could to some extent invalidate inferences derived from the analysis. Estimates of additive and dominance genetic variance cannot be accurately obtained from a diallel analysis in the presence of epistasis, which skews the relative contribution of the genotypic values associated with the parents [18]. Previous research indicates that inheritance of oil concentration is a more complex genetic system than a simple additive-dominance model $[19,20]$. Despite these constraints, a diallel design can be used to estimate genetic variance components [21, 22] and combining abilities [18], although less reliably than if all assumptions in the genetic model were satisfied.

Because our study is based on a limited number of selected parents, the inferences are applicable to these populations alone. Authors have suggested that genetic variance estimates and therefore heritability estimates are unreliable in a fixed model $[18,23,24]$. However, the preponderance of evidence from this study and other published papers clearly demonstrate the importance of additive effects in the inheritance of peanut oil concentration $[2-4,20]$ and seed mass $[4,25]$.

The importance of additive effects, as measured by GCA, is reflected in the high narrow-sense heritability estimates $\left(h^{2}\right)$ for oil concentration and 50 SMK. Wilson et al. [20] also reported a high $h^{2}$ for oil concentration, and the trait exhibited continuous variation in a normal distribution in $F_{2}$ generations. The high heritability estimates indicate that these traits are responsive to selection.

The inverse relationship between oil concentration and seed weight was also observed in previous studies, which implies that the use of metabolic resources to produce elevated oil concentration in peanut seeds causes a concurrent decrease in cotyledon weight $[6,7]$. Observed reductions in kernel mass with increasing oil content in corn breeding lines by Miller et al. [8] were determined to be a function of reduced endosperm weight compared to the expected increase in germ weight. Breeding line 31-08-05-02 contains oil genes derived from diploid wild-species, which typically have a much lower seed mass compared to cultivated, tetraploid genotypes [26]. This inverse relationship also was reflected in GCA values of the parents, because the two parents with positive GCA values for oil concentration had negative GCA values for 50 SMK and OPS. Although a negative correlation existed between seed mass and oil concentration, there were outliers within $F_{2}$ progeny derived from 31-08-05-02 that had high OPS compared to the plot average.

\section{Conclusions}

Progress can be made toward developing seed with improved oil concentration since the vast majority of variation for 
TABLE 4: Estimates of SCA effects and standard errors for oil concentration in $\mathrm{g} \mathrm{kg}^{-1}$, weight of 50 sound mature kernels (50 SMK) in grams, and mean milligrams oil produced per SMK (OPS) in a four-parent $F_{2}$ diallel of peanut.

\begin{tabular}{|c|c|c|c|c|}
\hline \multirow{2}{*}{ Parent } & \multicolumn{4}{|c|}{ Parent } \\
\hline & Tamrun OL01 & Tamrun OL07 & Lub 268 & $31-08-05-02$ \\
\hline \multirow{3}{*}{ Tamrun OL01 } & $0.75 a$ & $8.65^{* *}$ & $-12.31^{* *}$ & 2.91 \\
\hline & 0.11 & -0.44 & $0.97^{*}$ & -0.64 \\
\hline & -4.64 & 2.55 & 2.77 & -0.67 \\
\hline \multirow{3}{*}{ Tamrun OL07 } & & 3.81 & -2.41 & $-10.06^{* *}$ \\
\hline & & $1.04^{*}$ & -0.58 & -0.11 \\
\hline & & $11.48^{*}$ & $-7.55^{*}$ & -6.48 \\
\hline \multirow{3}{*}{ Lub 268} & & & $14.13^{* *}$ & 0.59 \\
\hline & & & -0.54 & 0.14 \\
\hline & & & 3.42 & -1.36 \\
\hline \multirow{3}{*}{ 31-08-05-02 } & & & & $6.56^{*}$ \\
\hline & & & & 0.52 \\
\hline & & & & 5.80 \\
\hline & Oil concentration & 50 SMKs (g) & OPS (mg) & \\
\hline $\mathrm{SE}\left(s_{i i}\right)$ & 3.3 & 0.51 & 4.89 & \\
\hline $\mathrm{SE}\left(s_{i j}\right)$ & 2.5 & 0.38 & 3.42 & \\
\hline
\end{tabular}

${ }^{\mathrm{a}}$ Top number oil concentration; middle 50 SMK; bottom OPS.

${ }^{*, * *}$ indicate terms that are significant at the 5 and $1 \%$ levels of probability, respectively.

this trait is genetic. Because the relationship between oil concentration and seed mass is negative in our populations, large segregating populations will need to be evaluated to improve both traits. The low narrow-sense heritability of OPS is a product of the negative correlation between oil concentration and seed weight in our populations and error associated with these measurements. Based on our data, early-generation selection based on OPS in these populations in this environment would not be effective but selection for either oil concentration and/or seed size would be. Given that higher seed yields result in higher total oil yields, a selection index that maximizes one trait while maintaining performance of the second may be an appropriate approach to improving oil yield in peanut.

\section{References}

[1] USDA National Agricultural Statistics Service, http://quickstats .nass.usda.gov/.

[2] E. E. Sykes and T. E. Michaels, "Combining ability of Ontariogrown peanuts (Arachis hypogaea L.) for oil, fatty acid, and taxonomic characters," Peanut Science, vol. 13, no. 2, pp. 93-97, 1986.

[3] T. G. Isleib, H. E. Pattee, and F. G. Giesbrecht, "Oil, sugar, and starch characteristics in peanut breeding lines selected for low and high oil content and their combining ability," Journal of Agricultural and Food Chemistry, vol. 52, no. 10, pp. 3165-3168, 2004.

[4] A. Layrisse, J. C. Wynne, and T. G. Isleib, "Combining ability for yield, protein and oil of peanut lines from South American centers of diversity," Euphytica, vol. 29, no. 3, pp. 561-570, 1980.

[5] S. L. Dwivedi, R. Jambunathan, S. N. Nigam, K. Raghunath, K. R. Shankar, and G. V. S. Nagabhushanam, "Relationship of seed mass to oil and protein contents in peanut (Arachis hypogaea L.)," Peanut Science, vol. 17, no. 2, pp. 48-52, 1990.

[6] K. T. Holley and R. O. Hammons, Strain and Seasonal Effects on Peanut Characteristics, vol. 32 of Georgia Agriculture Experiment Station Research Bulletin, University of Georgia, 1968.

[7] S. H. Patil, "Induced mutations for improving quantitative characters of groundnut," Indian Journal of Genetics and Plant Breeding, vol. 32, no. 3, pp. 451-459, 1972.

[8] R. L. Miller, J. W. Dudley, and D. E. Alexander, "High intensity selection for percent oil in corn," Crop Science, vol. 21, no. 3, pp. 433-437, 1981.

[9] Z. Y. Hu, W. Hua, L. Zang et al., "Seed structure characteristics to form ultrahigh oil content in rapeseed," PLoS ONE, vol. 8, no. 4, Article ID e62009, 2013.

[10] K. Liu, F. Orthoefer, and E. A. Brown, "Association of seed size with genotypic variation in the chemical constituents of soybeans," Journal of the American Oil Chemists' Society, vol. 72, no. 2, pp. 189-192, 1995.

[11] V. R. Pantalone, G. J. Rebetzke, R. F. Wilson, and J. W. Burton, "Relationship between seed mass and linolenic acid in progeny of crosses between cultivated and wild soybean," Journal of the American Oil Chemists' Society, vol. 74, no. 5, pp. 563-568, 1997.

[12] R. L. F. Gomes and A. C. D. A. Lopes, "Correlations and path analysis in peanut," Crop Breeding and Applied Biotechnology, vol. 5, pp. 105-110, 2005.

[13] C. E. Simpson, M. R. Baring, A. M. Schubert et al., "Registration of Tamrun OL01 peanut," Crop Science, vol. 43, no. 6, article 2298, 2003.

[14] M. R. Baring, C. E. Simpson, M. D. Burow et al., "Registration of Tamrun OL07 peanut," Crop Science, vol. 46, no. 6, pp. 27212722, 2006.

[15] C. E. Simpson, J. L. Starr, S. C. Nelson, K. E. Woodward, and O. D. Smith, "Registration of TxAG-6 and TxAG-7 peanut germplasm," Crop Science, vol. 33, no. 6, article 1418, 1993. 
[16] B. Griffing, "Concept of general and specific combining ability in relation to diallel crossing systems," Australian Journal of Biological Science, vol. 9, no. 4, pp. 462-493, 1956.

[17] M. D. Burow and J. G. Coors, "DIALLEL: a microcomputer program for the simulation and analysis of diallel crosses," Agronomy Journal, vol. 86, no. 1, pp. 154-158, 1994.

[18] R. J. Baker, "Issues in diallel analysis," Crop Science, vol. 18, no. 4, pp. 533-536, 1978.

[19] H. D. Upadhyaya and S. N. Nigam, "Detection of epistasis for protein and oil contents and oil quality parameters in peanut," Crop Science, vol. 39, no. 1, pp. 115-118, 1999.

[20] J. N. Wilson, M. R. Baring, M. D. Burow, W. L. Rooney, and C. E. Simpson, "Generation means analysis of oil concentration in peanut," Journal of Crop Improvement, vol. 27, no. 1, pp. 85-95, 2013.

[21] B. I. Hayman, "The analysis of variance of diallel tables," Biometrics, vol. 10, no. 2, pp. 235-244, 1954.

[22] N. D. Wilson, D. E. Weibel, and R. W. McNew, "Diallel analyses of grain yield, percent protein, and protein yield in grain sorghum," Crop Science, vol. 18, no. 3, pp. 491-495, 1978.

[23] R. Bernardo, "Estimating genetic variances," in Breeding for Quantitative Traits in Plants, pp. 117-146, Stemma Press, Woodbury, Minn, USA, 2002.

[24] J. R. Sughroue and A. R. Hallauer, "Analysis of the diallel mating design for maize inbred lines," Crop Science, vol. 37, no. 2, pp. 400-405, 1997.

[25] S. L. Dwivedi, K. Thendapani, and S. N. Nigam, "Heterosis and combining ability studies and relationship among fruit and seed characters in peanut," Peanut Science, vol. 16, no. 1, pp. 14-20, 1989.

[26] H. T. Stalker and C. E. Simpson, "Germplasm resources in Arachis," in Advances in Peanut Science, H. E. Pattee and H. T. Stalker, Eds., pp. 14-53, American Peanut Research and Education Society, Stillwater, Okla, USA, 1995. 


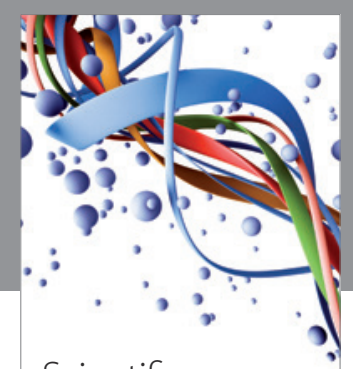

Scientifica
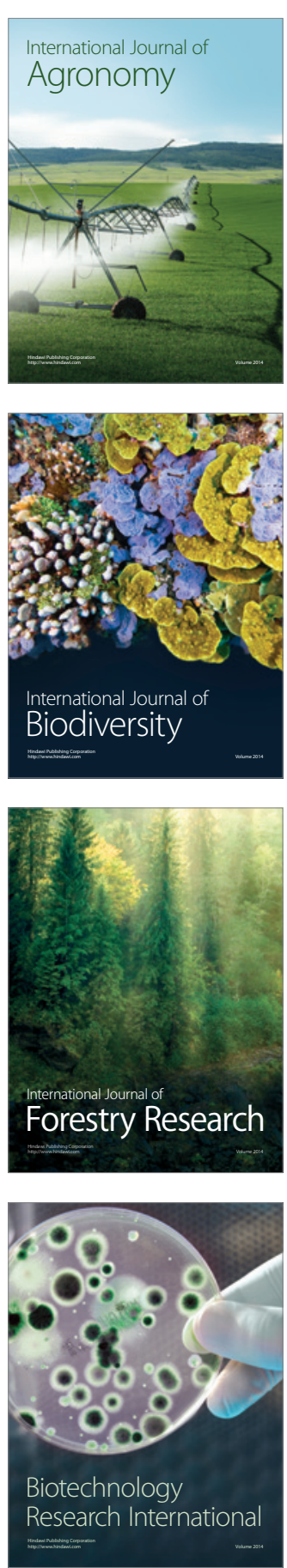
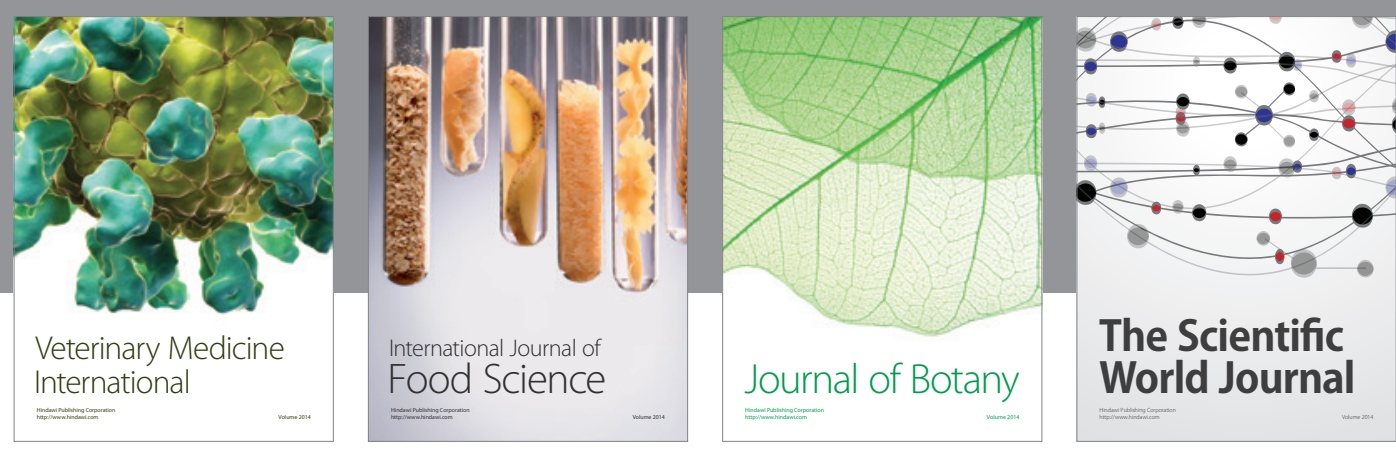

The Scientific World Journal
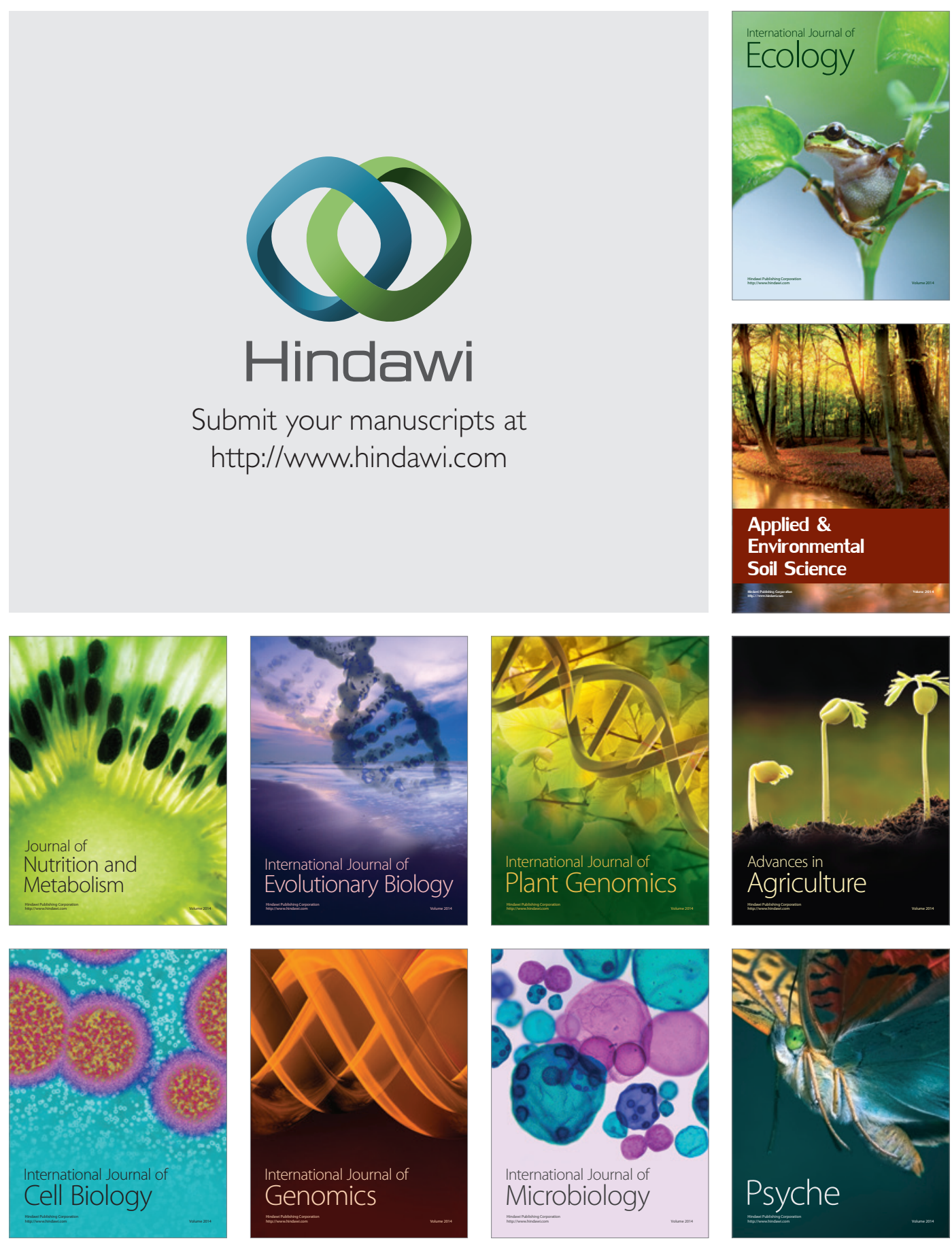